\title{
Mammary analog secretory carcinoma parotid gland: Case report of a recently described tumor with review of literature
}

\begin{abstract}
Mammary analog secretory carcinoma (MASC) is a low-grade malignant tumor of salivary glands. It is so named because of its cytohistopahological, immunohistological, and cytogenetic resemblance to secretory carcinoma of the breast. Since the first description of this tumor in 2010, about 70 cases have been reported in literature. We report a case of this recently described tumor in a 21 -year-old female. The radiological diagnosis of her parotid swelling was pleomorphic adenoma. The cytological evaluation was suggestive of oncocytoma. The histopathology showed a low-grade malignant neoplasm and the differential included papillary variant of acinic cell carcinoma, oncocytic variant of mucoepidermoid carcinoma, and MASC. Immunohistochemistry confirmed the diagnosis of MASC. We have included a brief review of literature.
\end{abstract}

Keywords: Acinic cell carcinoma, mammary analog secretory carcinoma, mucoepidermoid carcinoma

\section{INTRODUCTION}

Mammary analog secretory carcinoma (MASC), a recently described salivary gland neoplasm, is so named because of its histological, immunohistochemical, and cytogenetic resemblance to secretory carcinoma of the breast. It is a solitary, well-circumscribed tumor, found in the age range of 14-78 years, with parotid being the most common site. Cytologically, it shows features of a low-grade carcinoma. Histopathologically, secretions are prominently associated with a variety of patterns. The differential includes acinic cell carcinoma (ACC), low-grade mucoepidermoid carcinoma (MEC), and adenocarcinoma not otherwise specified (NOS). IHC can support the diagnosis and confirmation is obtained by demonstration of the characteristic ETV6-NTRK3 fusion gene.

\section{CASE REPORT}

An unmarried, 21-year-old female patient presented with complaints of painless swelling in front of the right earlobe for 1 year. Initially pea sized, it gradually increased to the current size. There was a nontender, firm right parotid region swelling measuring $3 \mathrm{~cm}$ in size. It was fixed to the underlying

\begin{tabular}{|l|c|}
\hline \multicolumn{2}{|c|}{ Access this article online } \\
\hline \multirow{2}{*}{$\begin{array}{l}\text { Website: } \\
\text { www.asjo.in }\end{array}$} & Quick Response Code \\
\cline { 2 - 2 } DOI: & \\
10.4103/ASJO.ASJO_61_16 & \\
& \\
\hline
\end{tabular}

structures but not to the skin. Jaw movements were normal. Cervical lymph nodes were not palpable. A computerized tomography of the head and neck revealed a well-defined moderately enhancing lesion measuring $25 \mathrm{~mm} \times 21 \mathrm{~mm}$ involving the superficial lobe of right parotid gland, without necrosis or calcification. It was abutting the masseter muscle with loss of fat planes between the two [Figure 1]. Multiple enlarged bilateral submandibular and upper internal jugular lymph nodes were noted. The radiological diagnosis was pleomorphic adenoma. Fine-needle aspiration biopsy smears were highly cellular with loosely cohesive clusters and sheets of cells on a background of proteinaceous material, red blood cells and hemosiderin laden macrophages. An arborizing papillary arrangement was seen. The cells were medium sized having moderate amount of eosinophilic cytoplasm

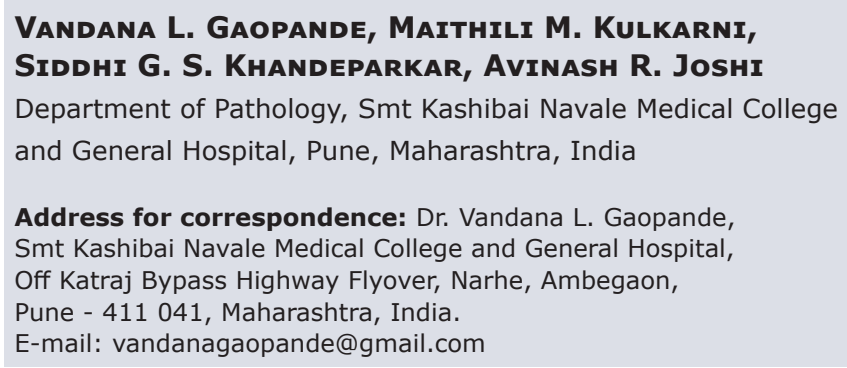

Vandana L. Gaopande, MaIthili M. Kulkarni, SiddhI G. S. Khandeparkar, Avinash R. Joshi Department of Pathology, Smt Kashibai Navale Medical College and General Hospital, Pune, Maharashtra, India

Address for correspondence: Dr. Vandana L. Gaopande, Smt Kashibai Navale Medical College and General Hospital, Off Katraj Bypass Highway Flyover, Narhe, Ambegaon, Pune - 411 041, Maharashtra, India.

E-mail: vandanagaopande@gmail.com

This is an open access article distributed under the terms of the Creative Commons Attribution-NonCommercial-ShareAlike 3.0 License, which allows others to remix, tweak, and build upon the work non-commercially, as long as the author is credited and the new creations are licensed under the identical terms.

For reprints contact: reprints@medknow.com

How to cite this article: Gaopande VL, Kulkarni MM, Khandeparkar SGS, Joshi AR. Mammary analog secretory carcinoma parotid gland: Case report of a recently described tumor with review of literature. Asian $\mathrm{J}$ Oncol 2017;3:139-43. 
and round-to-oval nuclei which were mildly hyperchromatic, regular with central nucleolus. Occasional cell showed binucleation. Acinar arrangement was observed. Extracellular secretions which resembled thick colloid were observed in the background [Figure 2]. A diagnosis of oncocytoma with cystic change was offered. A right superficial parotidectomy was done. Intraoperatively, frozen section of level-two right cervical lymph node was negative for metastasis, which was confirmed after routine processing. The surgical specimen measured $6 \mathrm{~cm} \times 2.5 \mathrm{~cm} \times 2.5 \mathrm{~cm}$ and revealed a firm, round, encapsulated tumor measuring $2.5 \mathrm{~cm} \times 2 \mathrm{~cm} \times 2 \mathrm{~cm}$ with gray-white cut surface showing hemorrhagic areas [Figure 3]. Areas of possible capsular breach were identified. Sections of tumor showed partial encapsulation. The tumor cells were arranged in sheets, nests, glandular, papillary, and microcystic pattern. The individual tumor cells resembled oncocytes, i.e., they were large having abundant granular eosinophilic

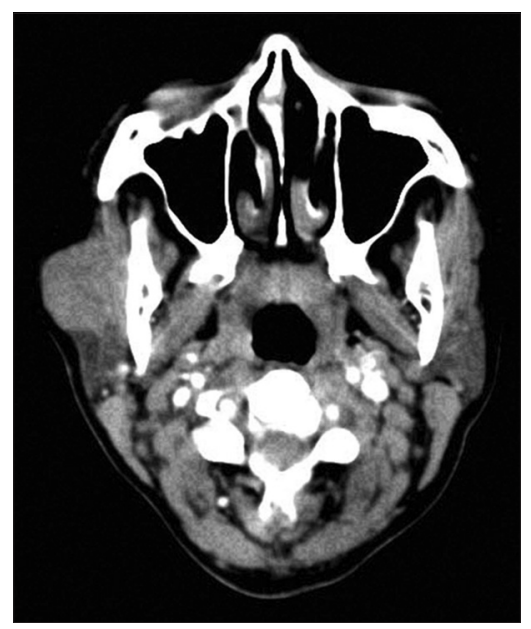

Figure 1: Computerized tomography head: A well-defined moderately enhancing lesion involving the superficial right parotid gland and abutting the masseter muscle with loss of fat planes between the two

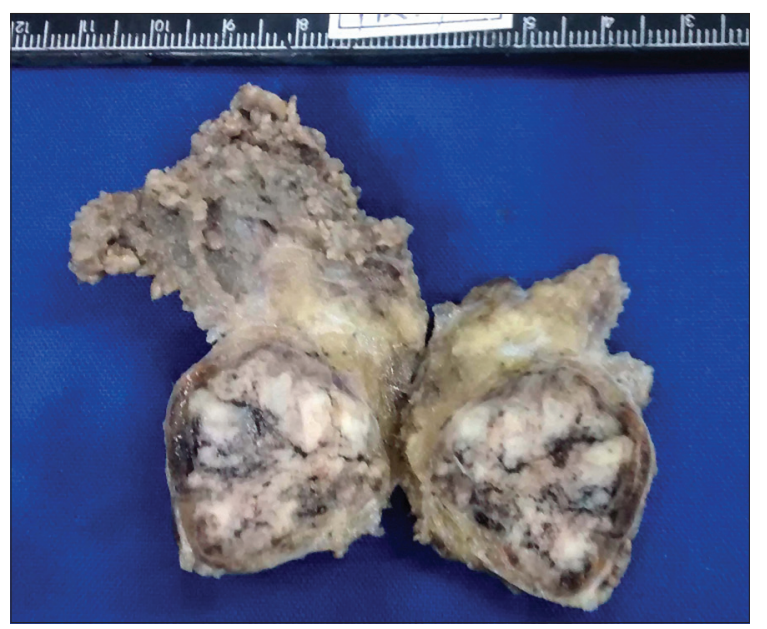

Figure 3: Gross photograph: A capsulated tumor having a gray-white and hemorrhagic cut surface cytoplasm and hyperchromatic, vesicular nuclei with single nucleoli. Hobnailing was noted focally. The glandular lumina contained abundant pink mucinous secretions. Clear cells were noted in few foci. Few mitoses were noted. Areas of hemorrhage with pigment-laden macrophages were seen. The tumor was seen to breach the capsule and infiltrate the surrounding muscle [Figure 4]. Normal serous salivary gland was identified at the periphery. A differential diagnosis of papillary variant of ACC and oncocytic variant of MEC and MASC was offered. The IHC findings of the tumor are given in Table 1 [Figures 5 and 6].

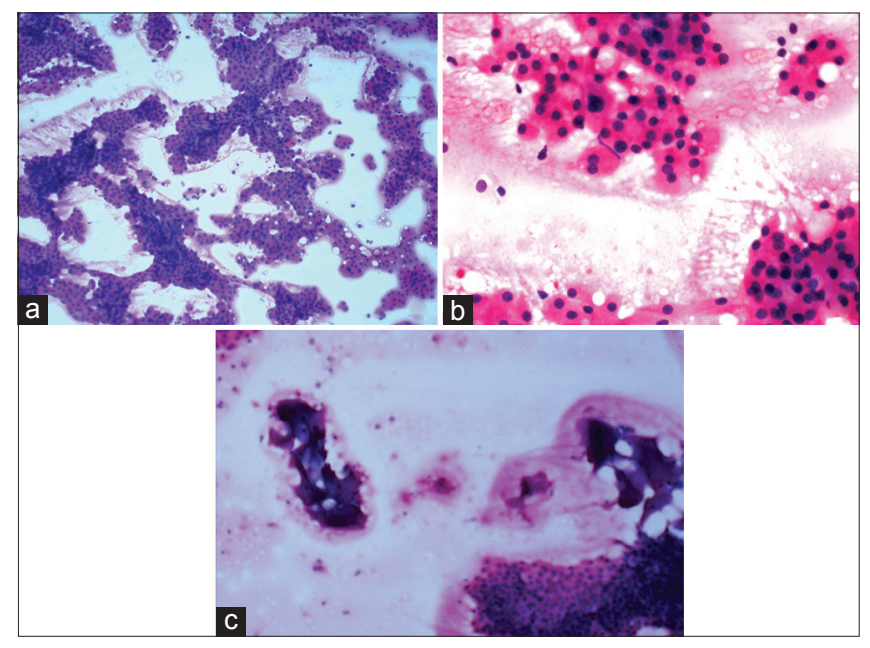

Figure 2: Fine-needle aspiration biopsy smears: (a) showing high cellularity and arborizing papillary structures ( $H$ and $E, \times 100)$, (b) showing the cell morphology resembling oncocytes and the acinar arrangement ( $H$ and $E, \times 400)$, (c) showing the secretions resembling thick colloid in background ( $H$ and $E, \times 100)$

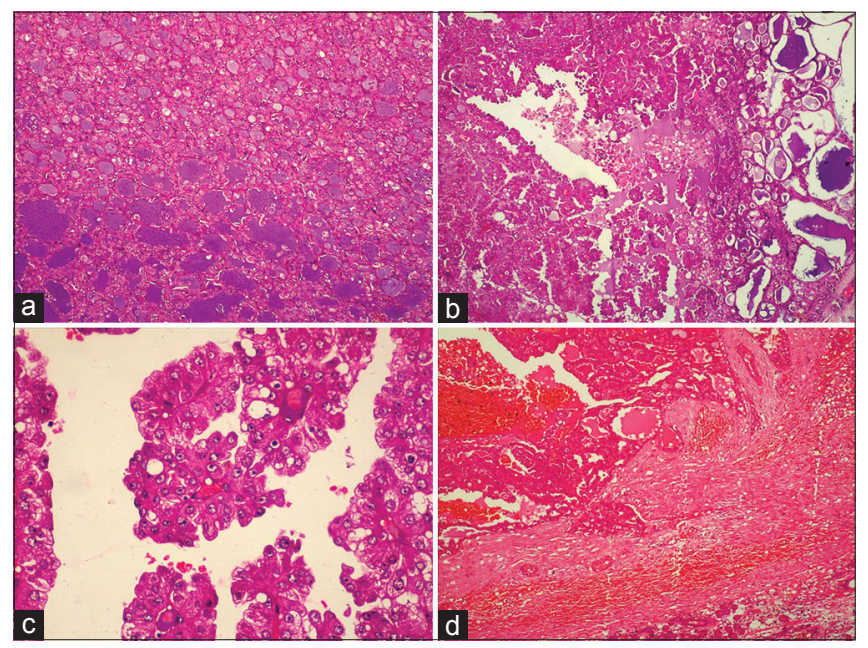

Figure 4: Histopathology of the tumor: (a) microcystic pattern ( $H$ and $E, \times 100$ ), (b) papillary structures $(H$ and $E, \times 100)$, with (c) lining of columnar cells having moderate amount of eosinophilic cytoplasm and vesicular nuclei, few with single nucleoli ( $\mathrm{H}$ and $\mathrm{E}, \times 400)$ and $(\mathrm{d})$ thick fibrous capsule between the tumor and normal salivary gland which is breached by the infiltrating tumor cells $(H$ and $E, \times 100)$ 
Table 1: Immunohistochemistry findings of the parotid tumor

\begin{tabular}{|c|c|c|c|c|}
\hline \multicolumn{3}{|r|}{ Positive markers } & \multicolumn{2}{|c|}{ Negative markers } \\
\hline $\begin{array}{l}\text { Name of } \\
\text { marker }\end{array}$ & Clone & Finding in tumor cells & Name of marker & Clone \\
\hline CK7 & Dako, 0V-TL12/30 & $\begin{array}{l}\text { Strong membranous and moderate cytoplasmic } \\
\text { positivity [Figure } 5 \text { a] }\end{array}$ & DOG-1 & Leica K9 \\
\hline CK19 & Dako, RCK108 & Strong membrane positivity [Figure $5 b]$ & P-63 & Novocastra 7JUL \\
\hline EMA & Dako, E29 & Strong membrane positivity on luminal side[Figure $5 c]$ & MUC1 & Novocastra Ma695 \\
\hline Vimentin & Dako, v9 & Strong cytoplasmic positivity [Figure 5d] & MUC2 & Novocastra Ccp58 \\
\hline S-100 & Leica & Moderate-to-strong cytoplasmic and nuclear positivity [Figure 6a] & CEA & Novocastra CD66e \\
\hline HMW-CK & Leica $34 \beta \mathrm{E} 12$ & Moderate-to-strong membranous positivity [Figure 6b] & SMA & Dako 1A4 \\
\hline Her2 & Novocastra CB11 & Strong cytoplasmic positivity [Figure 6c] & ER & Novocastra $6 \mathrm{~F} 11$ \\
\hline \multirow[t]{2}{*}{ Ki-67 } & Novocastra HM1 & Proliferative index 8\% [Figure 6d] & PR & Novocastra PGR312 \\
\hline & & & EGFR & Leica EGFR25 \\
\hline
\end{tabular}

EMA - Epithelial membrane antigen; CK - Cytokeratin; EGFR - Epidermal growth factor receptor; HMW - High molecular weight; DOG-1 - Discovered on GIST; CEA - Carcinoembryonic antigen; SMA - Smooth muscle actin; ER - Estrogen receptor; PR - Progesterone receptor; Her2 - Human epidermal growth factor receptor 2; GIST - Gastrointestinal stromal tumor; MUC - Mucin

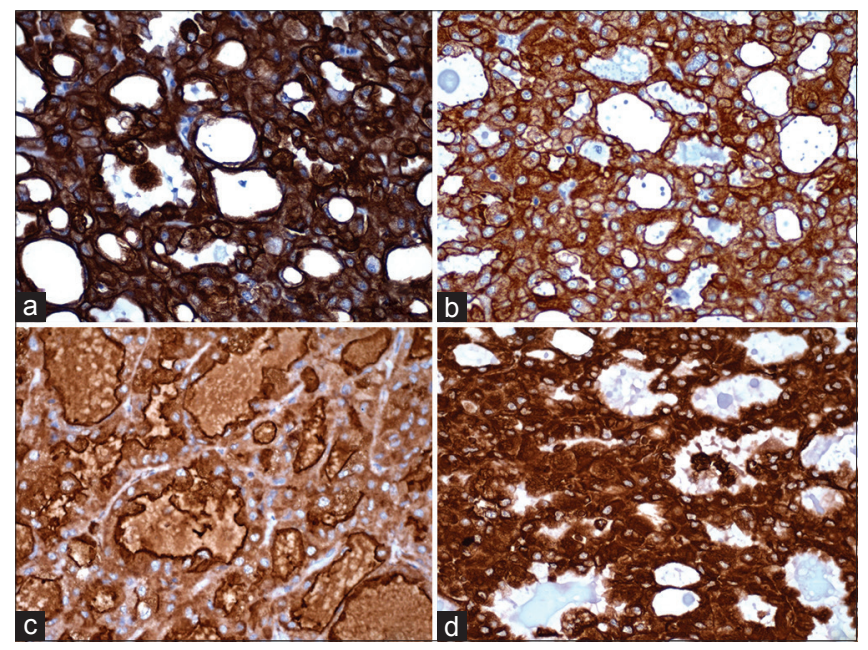

Figure 5: Immunoreactivity for (a) CK7, (b) CK19, (c) EMA, and (d) vimentin $(\times 400)$

The luminal secretions were periodic acid-Schiff(PAS) positive with and without diastase and alcian blue positive [Figure 7]. Occasional cell showed coarse, globular cytoplasmic PAS positivity. With the above findings, a final diagnosis of MASC was offered.

\section{DISCUSSION}

The first report of MASC was by Skálová et al. in 2010. They published a case series of 16 primary salivary gland tumors which were histologically similar to secretory breast carcinoma, expressed the same immunomarkers, and showed the presence of the characteristic translocation ETV6-NTRK. ${ }^{[1]}$ Since then, $>70$ cases have been reported in the literature..$^{[2]}$

MASC may arise from any major or minor salivary gland, but parotid is the most common reported site. ${ }^{[2]}$ Bishop et al. claimed that most alleged nonparotid ACCs represent

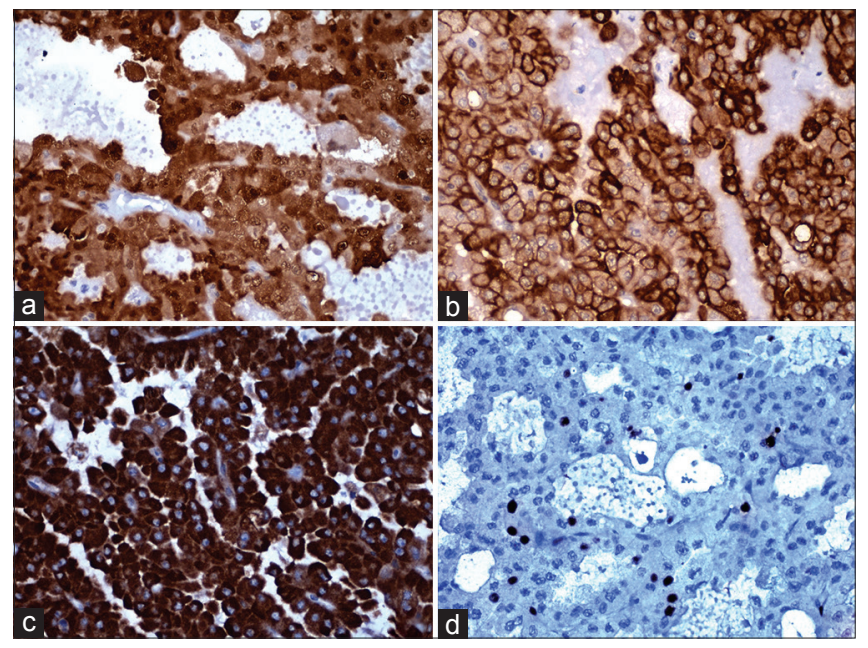

Figure 6: Immunoreactivity for (a) S100, (b) HMW-CK, (c) Her2, and (d) Ki67 (×400)

MASC. ${ }^{[3]}$ The mean age of presentation of MASC is 47 years (14-78 years) with slight male preponderance. Generally, slow-growing, painless, firm mass is the presenting symptom. ${ }^{[2]}$

Cytologically, high cellularity, cells in sheets, and cohesive clusters are characteristic. Acinar structures, papillary structures, and tubuloglandular patterns are seen. Bright pink filamentous matrix is admixed with the cells. Individual cells are round to polygonal having abundant vacuolated cytoplasm. Some cells with eosinophilic granular cytoplasm are also seen. The nuclei are uniform, round, and eccentric and show a small distinct nucleolus. The $\mathrm{N}: \mathrm{C}$ ratio is normal. Mitotic figures are not seen. Extracellular material which may be abundant is described. ${ }^{[4]}$ Bishop et al. mentioned two cytological patterns. One with a granular or cystic smear background and tumor fragments showing irregular and jagged outer borders. The cells showed round-to-oval 
Gaopande, et al.: Mammary analog secretory carcinoma parotid gland

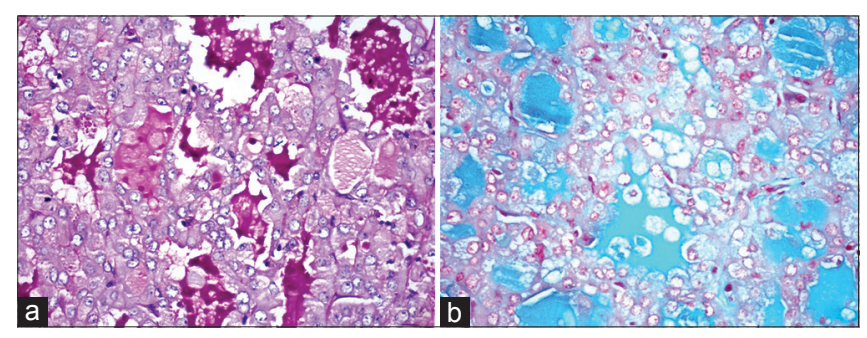

Figure 7: Special stains: (a) PAS-positive and (b) alcian blue-positive luminal secretions $(\times 400)$

uniform nuclei and small nucleoli with occasional cell showing cytoplasmic vacuoles. No matrix material or spindled stromal element was seen. The second pattern shows predominantly single cells admixed with histiocytes and granular debris. The neoplastic cells are large, round to polygonal with well-defined cytoplasmic borders and moderate amount of vacuolated cytoplasm. Cytoplasm is not granular. Naked nuclei are seen ${ }^{[5]}$ In this case series, the differential diagnosis considered included MEC, ACC, pleomorphic adenoma, and sebaceous gland neoplasm. ${ }^{|5|}$ Fine needle aspiration cytology (FNAC) of the present case showed cells resembling oncocytes. The features which did not favor the diagnosis of oncocytoma were papillary arrangement of cells and the extracellular secretions observed in background. A report describes the cytology of MASC as showing monomorphic population of cells with round nuclei, prominent nucleoli and abundant, eosinophilic foamy cytoplasm; forming papillary groups with transgressing vessels. ${ }^{[6]}$ MASC should be included in the differential diagnosis of FNA specimens diagnosed as oncocytic salivary gland neoplasms or suspicious for AC. ${ }^{[6]}$

MASC is a solitary well-circumscribed, unencapsulated tumor. ${ }^{[2]}$ In our case, a distinct fibrous capsule was found with tumor infiltrating through it focally. The cut surface of the mass may be gray-white, brown, or yellow and cystic component may be present. The tumor size is variable $(0.2-5.5 \mathrm{~cm}){ }^{[2]}$ The presence of capsule, cystic cut surface, and capsular invasion in MASC has been reported ${ }^{(7)}$ MASC shows a variety of patterns histopathologically. Tubular arrangement, microcystic pattern, macrocysts, or papillary arrangement are all observed. Secretions are always seen, and they vary from light pink and frothy to brightly eosinophilic and colloid like. The tumor cells resemble apocrine cells or oncocytes because of the eosinophilic granular cytoplasm. Vacuolated and clear cells may be seen. Tumor cell nuclei are oval with open chromatin and a single variably prominent nucleolus. Mitoses are few (0-1 per 10 hpf). Necrosis is absent. Lymphovascular invasion is not found and perineural invasion is rare. The luminal secretions are PAS positive with and without diastase digestion, mucicarmine positive and alcian blue positive. $^{[2,4]}$

The cytopathological differential diagnosis includes many low-grade epithelial neoplasms such as low-grade MEC and ACC. This is because of the vacuolated or cleared cells seen in MASC. A mixture of squamous cells, intermediate cells, and mucin-containing cells with extracellular mucin is characteristic of MEC. ACC is characterized by basophilic cytoplasmic granules, macronucleoli, and abundant arborizing vessels. ${ }^{[5]}$ In the present case, the cytological report was oncocytoma because of the strikingly prominent eosinophilic granular cytoplasm of the tumor cells. The arborizing papillary arrangement and the prominent extracellular eosinophilic secretions were the features not favoring diagnosis of oncocytoma.

The histopathological differential diagnosis includes ACC, MEC, and adenocarcinoma NOS. The characteristic basophilic zymogen cytoplasmic granules which are PAS positive are found only in ACC. ${ }^{[2]} \mathrm{A}$ squamous component is never a feature of MASC. ${ }^{|2|}$ The differential of MASC should include cystadenoma of salivary gland. ${ }^{[7]}$ In the present case, the histopathological differential included papillary variant of ACC and oncocytic variant of MEC, both of which were excluded by IHC.

Immunohistochemistry (IHC) helps to distinguish between these tumors. MASC is immunoreactive for CK7, CK18, EMA, S-100, vimentin, mammaglobin, and STAT5a. ${ }^{[2]}$ ACC shows DOG-1 immunoreactivity. ${ }^{[8]}$ MASC is negative for ER, PR, SMA, and calponin. ${ }^{[2]}$ Immunoreactivity for P63 and MUC proteins is a characteristic of MEC. ${ }^{[9,10]}$ It has been reported that mammaglobin may be used as a proxy immunomarker for ETV6-NTRK3 translocation in diagnosis of MASC. Although a diagnosis of MASC should not be made based solely on mammaglobin immunoreactivity, strong mammaglobin staining is confirmatory for those tumors that exhibit classic MASC morphology even in the absence of testing for ETV6 rearrangement. ${ }^{[11]}$

MASC like the secretory carcinoma of the breast has a balanced chromosomal translocation $\mathrm{t}(12,15)(\mathrm{p} 13 ; \mathrm{q} 25)$. As a result, a fusion gene ETV6-NTRK3 is formed, the protein product of which is a chimeric oncoprotein tyrosine kinase. Tests such as fluorescent in situ hybridization or reverse transcriptase polymerase chain reaction are used to detect this molecular defect. ${ }^{[2]}$

MASC is currently considered as low-grade carcinoma with a favorable prognosis. Few local recurrence, lymph node metastasis, and disease-related deaths are reported. ${ }^{[2]}$ 


\section{CONCLUSION}

MASC should be included in the differential of oncocytic neoplasms of salivary glands. IHC is helpful in ruling out the histopathological differentials such as papillary variant of ACC and oncocytic variant of MEC.

\section{Declaration of patient consent}

The authors certify that they have obtained all appropriate patient consent forms. In the form the patient(s) has/have given his/her/their consent for his/her/their images and other clinical information to be reported in the journal. The patients understand that their names and initials will not be published and due efforts will be made to conceal their identity, but anonymity cannot be guaranteed.

\section{Acknowledgments}

Authors did not receive funds from any source for this study.

Financial support and sponsorship

Nil.

\section{Conflicts of interest}

There are no conflicts of interest.

\section{REFERENCES}

1. Skálová A, Vanecek T, Sima R, Laco J, Weinreb I, Perez-Ordonez B, et al. Mammary analogue secretory carcinoma of salivary glands, containing the ETV6-NTRK3 fusion gene: A hitherto undescribed salivary gland tumor entity. Am J Surg Pathol 2010;34:599-608.

2. Bishop JA. Unmasking MASC: Bringing to light the unique morphologic, immunohistochemical and genetic features of the newly recognized mammary analogue secretory carcinoma of salivary glands. Head Neck Pathol 2013;7:35-9.

3. Bishop JA, Yonescu R, Batista D, Eisele DW, Westra WH. Most nonparotid "acinic cell carcinomas" represent mammary analog secretory carcinomas. Am J Surg Pathol 2013;37:1053-7.

4. Skalova A. Mammary analogue secretory carcinoma of salivary gland origin: An update and expanded morphologic and immunohistochemical spectrum of recently described entity. Head Neck Pathol 2013;7 Suppl 1:S30-6.

5. Bishop JA, Yonescu R, Batista DA, Westra WH, Ali SZ. Cytopathologic features of mammary analogue secretory carcinoma. Cancer Cytopathol 2013;121:228-33.

6. Samulski TD, LiVolsi VA, Baloch Z. The cytopathologic features of mammary analog secretory carcinoma and its mimics. Cytojournal 2014;11:24.

7. Williams L, Chiosea SI. Mammary analogue secretory carcinoma mimicking salivary adenoma. Head Neck Pathol 2013;7:316-9.

8. Chênevert J, Duvvuri U, Chiosea S, Dacic S, Cieply K, Kim J, et al. DOG1: A novel marker of salivary acinar and intercalated duct differentiation. Mod Pathol 2012;25:919-29.

9. Sams RN, Gnepp DR. P63 expression can be used in differential diagnosis of salivary gland acinic cell and mucoepidermoid carcinomas. Head Neck Pathol 2013;7:64-8.

10. Handra-Luca A, Lamas G, Bertrand JC, Fouret P. MUC1, MUC2, MUC4, and MUC5AC expression in salivary gland mucoepidermoid carcinoma: Diagnostic and prognostic implications. Am J Surg Pathol 2005;29:881-9.

11. Bishop JA, Yonescu R, Batista D, Begum S, Eisele DW, Westra WH, et al. Utility of mammaglobin immunohistochemistry as a proxy marker for the ETV6-NTRK3 translocation in the diagnosis of salivary mammary analogue secretory carcinoma. Hum Pathol 2013;44:1982-8. 